\title{
Molecular Complexity of Lymphovascular Invasion: The Role of Cell Migration in Breast Cancer as a Prototype
}

\author{
Yousif A. Kariri ${ }^{a-c}$ Mohammed A. Aleskandarany ${ }^{a}$ Chitra Joseph ${ }^{a}$ \\ Sasagu Kurozumi ${ }^{a}$ Omar J. Mohammed ${ }^{c}$ Michael S. Toss ${ }^{a}$ Andrew R. Green ${ }^{a}$ c \\ Emad A. Rakha ${ }^{a}$

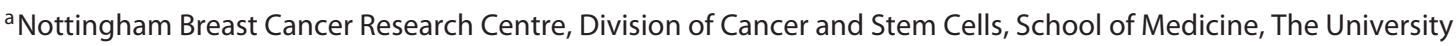 \\ of Nottingham, Nottingham, UK; ${ }^{\text {b } F a c u l t y ~ o f ~ A p p l i e d ~ M e d i c a l ~ S c i e n c e, ~ S h a q r a ~ U n i v e r s i t y, ~ R i y a d h, ~ S a u d i ~ A r a b i a ; ~}$ \\ 'Nottingham Breast Cancer Research Centre, Division of Cancer and Stem Cells, School of Medicine, University of \\ Nottingham Biodiscovery Institute, Nottingham, UK
}

\section{Keywords}

Vascular invasion · Breast cancer · Cell migration · Molecular mechanisms . Cancer stem cells

\begin{abstract}
Lymphovascular invasion (LVI) is associated with poor outcome in breast cancer (BC); however, its underlying mechanisms remain ill-defined. LVI in BC develops through complex molecular pathways involving not only the interplay with the surrounding microenvironment along with endothelial cells lining the lymphovascular spaces but also changes in the malignant epithelial cells with the acquisition of more invasive and migration abilities. In this review, we focus on the key features that enable tumour cell detachment from the primary niche, their migration and interaction with the surrounding microenvironment as well as the crosstalk with the vascular endothelial cells, which eventually lead to intravasation of tumour cells and LVI. Intravascular tumour cell survival and migration, their distant site extravasation, stromal invasion and growth are part of the metastatic cascade. Cancer cell migration commences with loss of tumour cells' cohesion initiating the invasion and migration processes which are usually accompanied by the accumulation of
\end{abstract}

specific cellular and molecular changes that enable tumour cells to overcome the blockades of the extracellular matrix, spread into surrounding tissues and interact with stromal cells and immune cells. Thereafter, tumour cells migrate further via interacting with lymphovascular endothelial cells to penetrate the vessel wall leading ultimately to intravasation of cancer cells. Exploring the potential factors influencing cell migration in LVI can help in understanding the underlying mechanisms of LVI to identify targeted therapy in BC.

(c) 2020 S. Karger AG, Basel

\section{Introduction}

The outcome of breast cancer (BC) has significantly improved in recent years [1, 2]. However, approximately $30 \%$ of early stage BC patients develop distant metastasis within 10 years following surgical resection of the primary tumour [3]. Lymphovascular invasion (LVI), which is defined as the presence of malignant cells within vascular or lymphatic spaces, is the major prerequisite for cancer progression and distant metastasis development [4-6]. Although LVI is strongly associated with advanced largesized tumours, it is also observed in small early stage BC karger@karger.com

www.karger.com/pat

(C) 2020 S. Karger AG, Base

Karger"
Emad A. Rakha

Division of Cancer and Stem Cells, School of Medicine

The University of Nottingham and Nottingham University Hospitals NHS Trust

Nottingham City Hospital, Nottingham NG5 1PB (UK)

Emad.Rakha@ nottingham.ac.uk 
Table 1. Key cancer migration-related genes in previous breast cancer gene signatures

\begin{tabular}{|c|c|c|c|c|}
\hline No. & Study & Cancer type & Total genes, $n$ & Genes associated with tumour cell migration \\
\hline 1 & $\begin{array}{l}\text { Mannelqvist } \\
\text { et al. [20], } 2014\end{array}$ & Breast cancer & 18 & $\begin{array}{l}\text { Downregulated: } \\
\text { FGFR2, ITIH5 } \\
\text { Upregulated: } \\
\text { MMP3, TNFAIP6, IL8, ANGPTL4, SERPINE1, COL8A1 }\end{array}$ \\
\hline 2 & Klahan et al. [21], 2017 & Breast cancer & 86 & $\begin{array}{l}\text { Downregulated: } \\
\text { UGCG, KRT14, KRT5, TFAP2B, COL4A1, ARADIA, STC1, } \\
\text { IL6ST, AGRTR1, EPAS1, AQPI, PLVAP, MUC20, ANKRD29 } \\
\text { Upregulated: } \\
\text { CYR61, GREM1, TNFSF11, PEX13, ORL1, TMEFF2, CXADR }\end{array}$ \\
\hline
\end{tabular}

and tumours with varying degrees of differentiation. There is a strong correlation between lymph node and distant metastasis and clinically detectable LVI in the primary BC [7]. This suggests that LVI may occur early in the process of carcinogenesis but the more common clinically detectable LVI, which is often observed in larger tumours, occurs late following the accumulation of molecular alterations more than those required for invasion of the ducto-lobular basement membrane. This observation supports the hypothesis that LVI could be targeted in BC despite the presence of stromal invasion. However, the challenges of targeting LVI in BC stem from being multifactorial, that is, it includes complex molecular mechanisms that drive LVI such as: tumour cell invasion and migration and the interplay between $\mathrm{BC}$ cells and various cells and structures in the surrounding tumour microenvironment including extracellular matrix (ECM), stromal cells, immune cells and endothelial cells. However, understanding the role of cancer cell invasion and migration in the development of LVI and differentiation of LVI-related molecular alterations from these driving tumour cell invasion and migration as an early mechanism associated with malignancy is a "difficult" but "beatable" challenge. Among various LVI-related pathways, this review focuses on the key features of cellular invasion, migration and their interaction with the surrounding microenvironment as principal factors leading to LVI.

The liberation of cancer cells from their parent tumours is a primary and essential event for daughter tumour cells to colonise and resettle in a secondary site [8]. It has been proposed that the detachment of cancer cells from the primary tumour in BC may be initiated by several genetic modifications in a sub-population of cells which enable them acquiring migratory potential [9]. In addition, several factors have been reported to influence tumour cell detachment such as enzyme activity, the rate of tumour growth and stress on cell release [10]. Beside the changes in cancer cell traits toward loss of epithelial and gain of certain mesenchymal markers, release of ECM-degrading enzymes, including matrix metalloproteinases (MMPs) accelerates the release of cells from the primary tumour tissue and subsequent invasion into tumour-adjacent tissues such as epithelial cell stratums and ultimately lymphatic vessels [11].

Structurally, lymphatic vessels have exiguous cellular junctions between the lining endothelial cells (i.e., fenestrated) and are surrounded by occasional pericytes and lack basement membranes which typically surround capillary vessels. This fenestrated structure facilitates access of $\mathrm{BC}$ cells into lymphatic vessels [12]. Tumour cells release growth factors and angiogenic factors which play a crucial role in tumour progression, angiogenesis and LVI. Lymphatic endothelial cells, in turn, interact with tumour cells, resulting in the secretion of small leucine-rich repeat proteoglycan, thus stimulating tumour cells to metastasise $[13,14]$. However, the key molecular mechanisms underlying LVI, whether the alterations are in the tumour cells, in the endothelial cells or in both remain to be deciphered. Thus far, HER2-positive tumour cells have been found to be a promotor for invasion and migration in BC resulting in highly aggressive tumours with poor outcome $[15,16]$. HER2 has been strongly associated with LVI via disrupting the architecture of tumour cells and encouraging their migratory activity and epithelial mesenchymal transition (EMT) to lose their adhesion $[17,18]$. Although the current standard therapeutic option is anti-HER2 therapy such as trastuzumab [15], pertuzumab [19] or lapatinib plus capecitabine [16], which has markedly improved the survival of HER2-positive $\mathrm{BC}$, the window is still open for further discovery of po- 


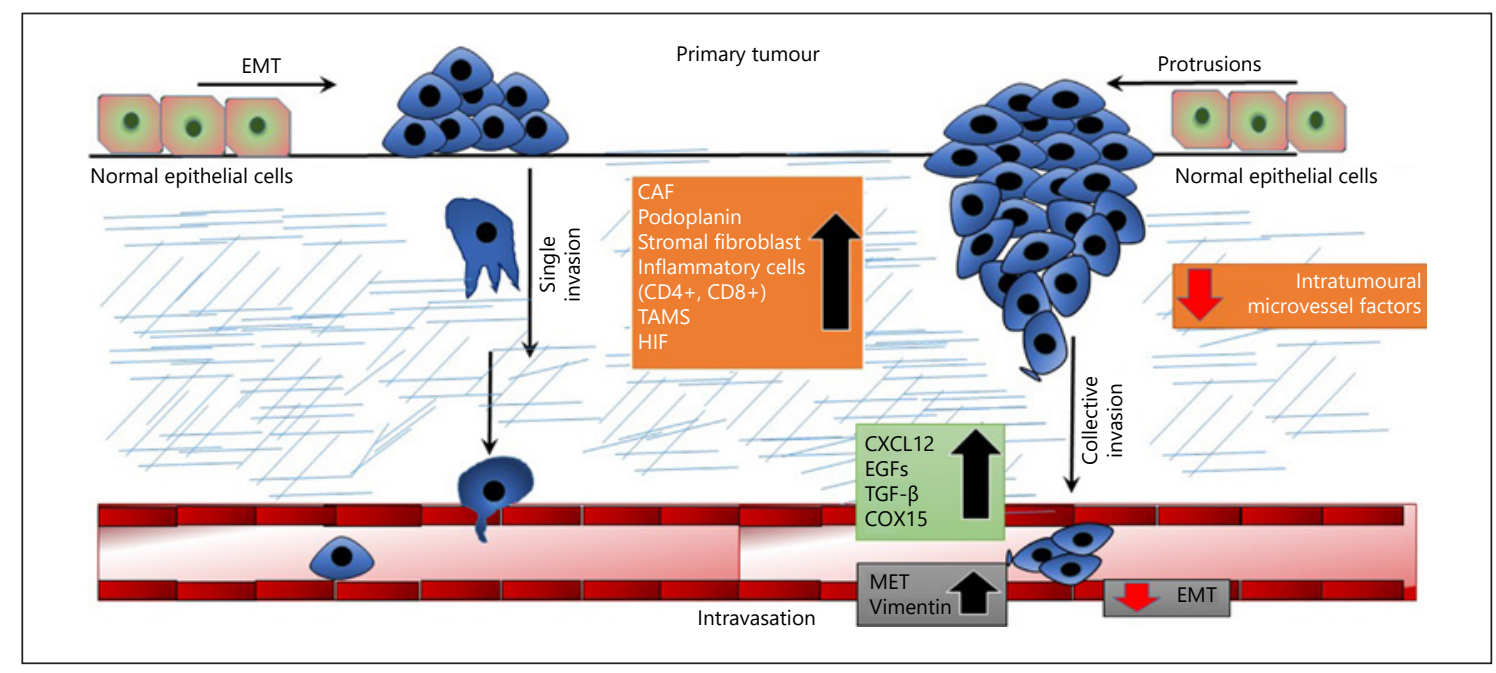

Fig. 1. A schematic diagram for the breast cancer cell migration process. The diagram shows the single and collective migration processes. In the single migration process, individual tumour cells are detached and migrate through the surrounding environment and then invade the lymphovascular channels. This process is controlled mainly through the epithelial mechanical transition process (EMT). In the collective migration/invasion process, the tumour grows in nests and sheets that protrude through the surrounding tumour stroma and invade the blood channels in adherent tumour

tential therapeutic targets such as those that can suppress LVI, thereby preventing distant metastasis and improving patient outcome.

\section{Cancer Cell Migration from the Primary Site towards the Lymphovascular System}

Cancer cell migration is an early process of carcinogenesis, and all invasive tumours exhibit migration abilities. Cell migration is essential for the disease progression and can be considered the initial stage of both LVI and tumour metastasis. Studies by our group as well as others have shown the association between LVI and genes related to cancer cell migration in BC (Table 1) [20, 21]. Although these genes appear to play a role in cancer cell migration and invasion, their precise role in LVI as an additional biological event remains difficult to be summarised, and the distinction of invasion/migration driving genes and those driving LVI remains blurred. Furthermore, the currently ongoing mechanistic studies, including 3D culture and co-culture with endothelial cells which allow investigating the intricate cell-cell and cellmatrix interactions may further help identifying the candidate genes or pathways driving LVI in BC. nests. EMT and mesenchymal epithelial transition (MET) factors play major roles in this process. Various tumour microenvironmental factors such as cancer-associated fibroblasts (CAFs), podoplanin, tumour-infiltrating lymphocytes, tumour-associated macrophages (TAMs) and hypoxia inducible factor (HIF) also play major roles in this process. Other endothelial-related factors such as CXCL12, epidermal growth factors (EGFs), tumour growth factor beta (TGF- $\beta$ ), and COX15 are elevated during the process of intravasation.

From a temporal standpoint, cell migration in BC is divided into 3 successive stages: (1) migration of the malignant epithelial cells (of the in situ disease) through the breast duct basement membrane (invasion), (2) migration through tumour stroma and interstitium (local spread) and (3) migration through the lymphovascular wall (intravasation into lymphovascular spaces). With the success of the latter stage, tumour cells present within vascular spaces initiate the process of distant metastasis (Fig. 1). As in a complex molecular mechanism, various factors, pathways and processes contribute in each step such as EMT of the invading tumour cells that might undergo changes in tumour cell motility and the interaction between tumour cells and tumour microenvironment.

During the stromal and ECM infiltration process, 2 distinct migratory patterns for tumour cells with potentially different molecular mechanisms have been documented: "single cancer cell migration" and "collective cancer cell migration" $[22,23]$.

\section{Single Cell Migration}

In single cancer cell migration, individual cancer cells detach from the primary tumour mass and lose epithelial polarity, acquire morphological characteristics of mesenchymal cells through the process of EMT [24]. The physical 
Table 2. Summary of genes/proteins associated with cancer cell migration in breast cancer

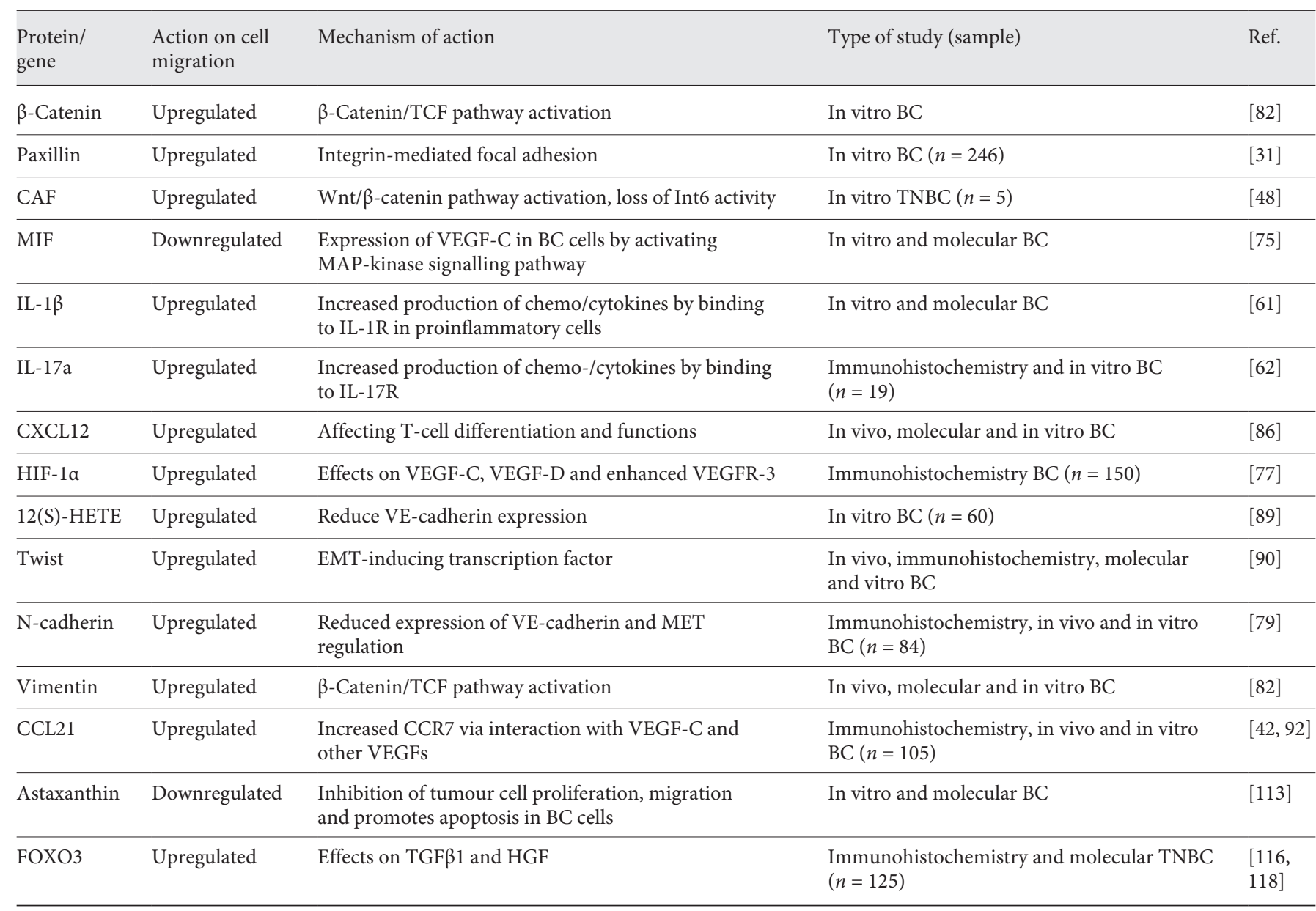

In vitro include MCF10, MCF7, T47D, MDA-MB-231, MDA-MB-435, BT549, and Hs578T.

process involved in single cell migration occurs when cancer cells migrate towards the lymphovascular channels through protease-dependent mesenchymal migration or protease-independent amoeboid-like migration. In the former, cells migrate based on the protease activity that cleaves ECM and facilitates cell entry into the vessels. In proteaseindependent amoeboid-like migration, cancer cells initiate mechanical forces that lead to promotion of cell permeation allowing them to cross the ECM instead of cleaving it [23]. Protease dependent mesenchymal migration is said to lead to slower tumour cell migration compared to proteaseindependent amoeboid-like migration [25].

\section{Collective Cancer Cell Migration}

In collective cancer cell migration, malignant cells destined for migration retain cellular cohesion to one another and migrate as detached clusters or remain connected to the primary tumour [26]. Force generation is a major prerequisite for collective cell migration where tumour cells advance by means of new protrusions. Clustering cancer cells develop integrin-mediated focal adhesions and membrane protrusions, which bind to actin filaments and aid tumour migration. ECM degradation involves the creation of an invasion path by the leading cells in the infiltrating tumour border through $\beta_{1}$-integrin-mediated focal attachment to ECM components such as fibronectin [27]. In addition, cytoskeletal adaptor proteins, including talin, paxillin, cortactin and vinculin, play a role in cancerassociated fibroblasts (CAFs) by mediating intracellular singling pathways and communication with tumour cells that promote cancer metastasis $[23,28]$.

Each of these migration patterns has specific characteristics and occurs through different biological mechanisms influenced by intrinsic vessel structures [22]. Col- 
lective cell migration is based only on the initial physical forces (protrusions) that are created by tumour cells themselves [22]. Furthermore, it usually executes vascular invasion through lymphatic spaces due to the presence of several fenestrations between cellular junctions within the lymphatic vessel structure which facilities intravasation as compared to blood vessels [23]. On the other hand, single cell migration can utilise both biological (mesenchymal and/or amoeboid) and physical forces, and therefore can invade lymphatic vessels [23]. Vascular invasion assessment with collective cell migration has better performance due to the difficulty in identifying single tumour cell invasion [25]. This difficulty may be also attributed to the lower chance of single cells surviving as compared to collective cell migration, which produces a unique form of cortical actin filament congregation around the cell junctions [23]. Proteins involved in the migration process are summarised in Table 2.

\section{The Role of Cellular Protrusions in Tumour Cell Migration}

Malignant cell protrusions, which consist of filopodia, lamellipodia and invadopodia, play a critical role in cancer cell migration via enhancing the physical forces leading to loss of adhesion between tumour cells (Fig. 2). Tumour cell migration, which occurs as a result of re-modulation in cell-cell and cell-matrix adhesion, involves reorganisation of actin cytoskeleton and F-actin rich membrane protrusions at the tumour edge. Tumour protrusions are of 2 varieties, namely invasive and non-invasive protrusion. Non-invasive protrusion is fundamentally associated with protease-dependent mesenchymal migration, such as in the bespoke EMT [23]. The invasive protrusion is involved in invadopodia which plays important roles in collective cancer cell migration and LVI in $\mathrm{BC}$ via upregulation of podoplanin without activation of EMT as reported in a recent clinical study $[23,29]$.

Non-invasive protrusion involving lamellipodia and filopodia usually occurs in association with single cell migration. Lamellipodia play an important role in cancer cell migration through loss of epithelial tissue cohesion with resultant tumour cell release from the primary tumour mass. Lamellipodia are produced by tumour cells where movement is initiated by forming new lamellipodia whilst promoting the loss of existing lamellipodia through forward contraction of the newly synthesised lamellipodia. This process helps tumour cells lose connection to the main tumour mass [30]. The focal adhesion adaptor proteins Scr and paxillin are used by non-invasive protrusion involved in lamellipodia and filopodia for ECM attachment via focal

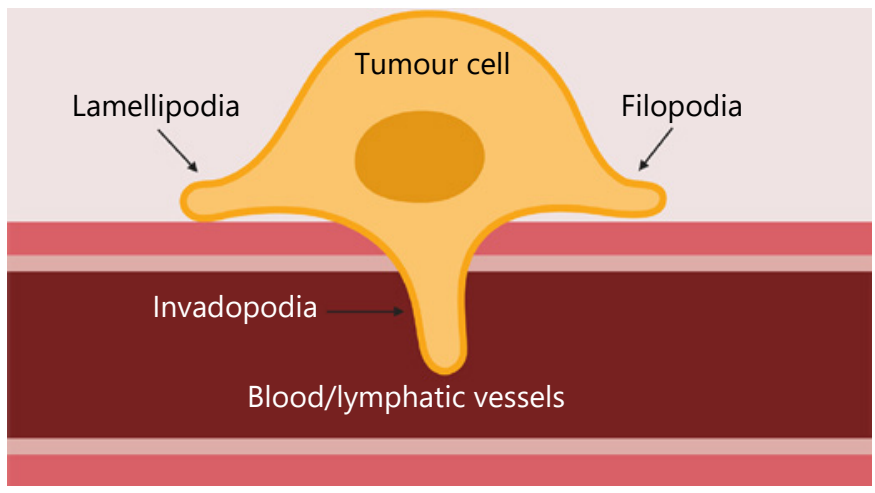

Fig. 2. A schematic diagram illustrating types of cellular protrusions. Filopodia and lamellipodia are non-invasive protrusion mechanisms which contribute to single cell migration by changing tumour cell cytoskeleton via initiating cell-physical forces resulting in loss of tumour cell-epithelial tissue adhesion. Invadopodia are invasive protrusions associated with cluster cell migration.

adhesion [31]. On the other hand, invadopodia affect the adhesion of cancer cells to the ECM which is crucial for invasion of lymphatic vessels and the invasion of tumour cells to the vascular system [32]. Formation of invadopodia has been observed in various cancer cell lines including BC [27]. This structure is formed when the degradation of ECM and cell adhesion junctions occur concomitantly. An invadopodium is composed of 3 main parts: proteolytic, invasive and adhesive domains. The proteolytic domain largely contains proteases such as serine proteases, for example, a disintegrin and metalloproteinase and MMPs [23]. The invasive domain is located inside the connection between invadopodial protrusion and ECM and is responsible for the regulation of actin as well as actin-linked proteins including mammalian Ena (MENA) and cortactin [33]. MENA is involved in invadopodium maturation and migration via the regulation of cortactin dephosphorylation [33]. Protein interactions occurring inside the invasive domain cause polymerisation of actin filaments leading to generation of mechanical forces which drive the cell towards the lymphatic vessels. Lastly, the adhesive domain is present at the tumour periphery connected to the ECM and functioned by integrin-mediated adhesion [23].

\section{Factors Attracting Tumour Cells toward the Lymphovascular System}

Before discussing the interplay between tumour cells and ECM detachment from the primary mass, some factors that may direct or attract the tumour cells towards the 
endothelial cells whether in lymphatic are considered. It has also been reported that the dysfunctional lymphatic network leads to the elevation of the interstitial fluid pressure, which in turn would be responsible for the directional locomotion of the migratory tumour cells toward the lymphatic at the tumour periphery [34]. By this mechanism, the tumour cells would be presented nearby the lymphatic system and passively increasing the opportunity of their intravasation into lymphatic channels. Nevertheless, attracting malignant cells towards both types of capillaries can also occur by active molecular mechanisms [35]. For example, vascular endothelial growth factor receptor-3 (VEGFR3) is solely expressed on lymphatic endothelial cells, and by binding to its ligand vascular endothelial growth factor (VEGF)-C, which is highly expressed in tumour cells, it may act as an attracting way which can also facilitate the tumour cells to leak into the vessels [35]. Previous reports have suggested that ECM also plays an important role in the process of cancer cell migration. MMPs are produced by stromal cells and are crucial for the progression of tumour cells owing to their capacity for ECM degradation remodelling and activation of matrix molecules and cytokines [36]. For instance, MMPs degrade matrix proteins and guide the tumour cells to lymphatic vessels, causing generation of chemoattractant mitogen-like hepatocyte growth factor (HGF), which in turn activates MMP2 and MMP9 [37]. Tumour cells are attracted by HGF along a gradient, which leads to rearrangements in the actin cytoskeleton via Rho- and Ras-like GTPases. These GTPases subsequently regulate the assembly and organisation of protrusions made from actin cytoskeleton [38]. The role of HGF in this directionality has been also verified in vitro, where tumour cells and macrophages, when seeded together, show a random bi-directional migration pattern [39]. However, sustained directionality of tumour cells akin to what was observed in vivo was retrieved in vitro when human umbilical vein endothelial cells were added to the culture within the same assay. These endothelial cells secrete the HGF required for the chemotactic gradient responsible for sustained directionality. However, when inhibiting the HGF signalling pathway between endothelial cells and tumour cells, the directional streaming of tumour cells become defective again [39].

\section{Interaction with the Surrounding Microenvironment}

Although the initial molecular alterations that lead to invasion and metastasis begin in transformed BC cells, these processes cannot be completed without sustenance from and interaction with cells in the microenvironment which can either promote or suppress tumour cell migration and invasion. Subsequently, BC cells interact with various types of stromal and immune cells in their vicinity such as stromal mesenchymal cells, fibroblasts, myofibroblasts, adipocytes, immune inflammatory cells, endothelial cells and pericytes lining lymphovascular spaces for intravasation [22, 40, 41].

The interplay between tumour cells and tumour microenvironment is complex, and the effect on cancer cell migration and invasion is mutual, being driven by both tumour cells and various components of the tumour microenvironment. Many molecules secreted by non-malignant cells in the microenvironment could influence tumour cell behaviour and promote tumour migration specifically toward lym phatic vessels. These molecules include $\mathrm{C}$ - $\mathrm{C}$ chemokine receptor-7-dependent paracrine effect and macrophage-derived VEGF-C acting through autocrine mechanisms [42].

\section{The Role of Myoepithelial Cells and Fibroblasts}

Typically, myoepithelial cells are considered natural tumour suppressors in breast tissue through their action as tumour gatekeepers preventing cancer cell proliferation, survival, invasion, migration and metastatic spread [43]. However, following interaction with BC cells which are capacitated for invasion, these stromal and immune cells become modified and execute divergent functions which promote $\mathrm{BC}$ cell migration and invasion. For instance, evidence indicates that CAFs, modified stromal fibroblasts/myofibroblasts [44], promote tumour growth, migration and invasion via enhancing $\mathrm{Wnt} / \beta$-catenin signalling, with subsequent activation of MMPs, which degrade the vessel walls, thereby facilitating BC cells' migration towards vessels [45]. CAFs also express podoplanin and VEGF-C, which affect intratumoral micro-vessels, regulate cancer cell migration, influence malignant, inflammatory and endothelial cells and play pivotal roles in tumourigenesis and invasion [29]. In LVI, podoplanin positivity is more frequent than CD31 or CD34 positivity and is associated with the development of nodal metastasis and poor clinical outcome $[29,46]$. CAFs are also a major source of $\mathrm{N}$-cadherin in $\mathrm{BC}$, thus affecting the tumour cells' migration by prompting them to leave the primary site and start the migration process [47]. Furthermore, stromal fibroblast transformation into CAFs could be promoted through the loss of interleukin (IL)6 , hence promoting $\mathrm{BC}$ cell migration and invasion [48]. 
The Role of Immune Cells and Inflammatory

\section{Mediators}

Inflammatory cells populating the tumour microenvironment play a critical role during LVI by enhancing cancer cell proliferation, migration and invasion [49]. In invasive cancer microenvironment, tumour-associated angiogenesis and lymphangiogenesis tend to produce an interconnecting vascular organisation of lymphatic and blood vessels which facilitate tumour interaction with other cell types such as lymphoid, haematopoietic and mesenchymal cells, resulting in remodelling of the ECM $[50,51]$. During tumour progression, malignant cells produce certain chemokines and cytokines that are mitogenic and/or chemoattractant for immune cells [50]. Infiltrating inflammatory cells, in turn, are activated to produce certain chemokines, cytokines and proteolytic enzymes, which prompt tumour migration, invasion and survival, and also stimulate endothelial cells for neoangiogenesis and lymphangiogenesis [50, 51]. There is an increasing interest in the role of immune cells and tumour-infiltrating lymphocytes (TILs) and their interaction with cancer cells to control tumour behaviour and response to therapy. Manipulation of this interaction is a fast-growing field, and several immune checkpoint inhibitors have been described in several solid cancers including $\mathrm{BC}$ which show highly promising results for therapy $[52,53]$. There is sufficient evidence to demonstrate that moderate and intense inflammation is associated with improved prognosis in triple-negative (TN) and HER2positive BC [54-56]. TILs comprise several types of immune cells, including tumour-promoting and tumoursuppressing cells. Cytotoxic T cells (CD8+ T cells) and natural killer $\mathrm{T}$ cells attack cancer cells and are considered to be tumour suppressor cells, whereas regulatory $\mathrm{T}$ cells (CD4+, and FOXP3+ T cells) inhibit immune responses to cancer cells and therefore can be considered as cancerpromoting cells. Conversely, CD4+ T lymphocytes are able to promote invasion via activation of the epidermal growth factor receptor (EFGR) signalling pathway [57]. Moreover, a CD4+ T-cell fraction (Tregs) can inhibit anti-tumour immune response by suppressing effector Tcells and is responsible for producing several members of the immunosuppressive cytokines family, including transforming growth factor- $\beta$ and IL-10 [58]. Therefore, CD4+ T cells enhance the migration of tumour cells and facilitate LVI by inhibiting the anti-tumour response through significant chemokine production.

Previous studies have demonstrated an association between LVI and tumour immune cell infiltration. For instance, LVI-positive squamous cell carcinoma of the tongue showed less CD4+ and CD8+ T cells, and lower CD4+/FOXP3+ T-cell and CD8+/FOXP3+ T-cell ratios, indicating that tumour progression is associated with a shift towards a more immunosuppressive environment [59]. CD8+ T cells induced by pre-existing tumour antigen, are downregulated by PD-1/ PD-L1 interactions [60]. Inflammatory factors are also involved in tumour migration through the release of pro-migratory factors. For instance, IL- $1 \beta$ plays an important role in BC migration, adhesion to lymphatic endothelial cells and transmigration by activating unique chemokines and cytokines using the IL-1R [61]. IL-17A also promotes BC cell migration and invasion by activating certain intracellular signalling pathways [62].

Macrophages have been shown to promote tumour progression in BC [63]. Tissue macrophages play a pivotal role in tumour angiogenesis through their inherent characteristics such as flexibility and mobility in enhancing endothelial tip-cell anastomosis and by regulating excessive vessel sprouting. Thus, they are suited to stimulate endothelial cells in different vessel segments to initiate contacts with other microenvironment molecules [64, 65]. Macrophages have been described to have both oncogenic and tumour-suppressing functions. Once CD8+ $\mathrm{T}$ cells interact with tumour cell antigens, they produce interferon gamma that is responsible for performing a tumouricidal activity via inducing macrophage tumour killing activity and/or antigens [66]. This results in suppression of LVI through decreasing tumour lymphatic microvascular density by producing extracellular vesicles, which break down neighbouring mesenchymal tumour stroma $[66,67]$. Contrasting this, macrophages also play a key role in promoting migration and invasion of tumour cells through production of epidermal growth factor which activates migration and invasiveness of malignant mammary epithelial cells [68]. Evidence from recent preclinical research studies has demonstrated that tumour-associated macrophages (TAMs) are one of the principal factors controlling tumour progression in many tumour types including BC [51]. TAMs are reported as having the greatest migratory capacity amongst haematopoietic cells [69]. TAMs have M2 macrophage phenotype (alternatively activated macrophages) in BC, which requires CD4+ T-cell derived IL-4 for activation [70]. Once activated, TAMs can enhance angiogenesis via IL-1, MMP2 and VEGFs [64]. These proteases and growth factors released by macrophages have the ability to instigate tumourigenesis and promote tumour progression [71]. Moreover, in BC stroma, TAM-derived cytokines can stimulate tumour invasiveness by enhancing their adhe- 
sion to the ECM [72]. VEGF-C expression is strongly associated with TAM expression in BC and is strongly correlated with developing lymphovascular tumour density and LVI [73]. Macrophage migration inhibitory factor (MIF), a pleiotropic inflammatory cytokine, promotes the migration of $\mathrm{BC}$ cells via controlling CD74 expression and hypoxia-inducible factor-1 (HIF-1) [74]. Zhang et al. [75] have indicated that MIF can regulate the level of VEGF-C in BC cells through activation of the MAP-kinase signalling pathway. This activation increases the invasive capacity of cancer cells by promoting TNF- $\alpha$, leading to increased protease levels, and allowing tumour cells' access into lymphatic vessels [76].

\section{The Effect of Hypoxic Microenvironment on LVI}

Hypoxia is also associated with cancer cell migration. HIF-1 $a$ drives tumour cell migration into a favourite "less hypoxic" environment. This promotes tumour progression by enhancing tumour cell survival, invasion, anaerobic metabolism and angiogenesis [77]. VEGF, which is strongly associated with angiogenesis, is also regulated by HIF-1 a [78]. Further, Schoppmann et al. [77] have suggested that HIF-1 $\alpha$ is strongly associated with BC LVI together with VEGF-C/D and their receptor VEGFR-3.

\section{Cellular Adhesion in LVI}

Loss of tumour cell-cell adhesion is an essential step and early event in tumour cell migration, stromal invasion and intravasation. Most tumour cells lose their adhesion to the primary tumour cell mass and migrate by undergoing EMT. Conversely, several mechanisms, including EMT and mesenchymal epithelial transformation (MET) are involved in tumour cell adhesion to lymphatic and or vascular endothelial (VE) cells [79]. MET is reversed EMT involving upregulation of E-cadherin and downregulation of $\mathrm{N}$-cadherin. $\mathrm{N}$-cadherin regulates the expression of VEcadherin in aggressive $\mathrm{BC}$ and hence promotes tumour progression [79]. Several changes including upregulation of E-cadherin are responsible for the $\mathrm{N}$-cadherin paralysis that leads to downregulation of several mesenchymal markers and changes in several morphological features, thus facilitating tumour cell adhesion to endothelial cells (due to reversal EMT to MET) [79]. Alternatively, VE-cadherin paralysis, which is a cadherin subtype produced by endothelial cells as a consequence of $\mathrm{N}$-cadherin downregulation, affects epithelial markers and endothelial cellcell junctions without influencing E-cadherin or MET process. Moreover, VE-cadherin is located on the cell mem- brane due to the disruption of VE-cadherin clusters which activates VE-ectodomain encouraging its clustering at intracellular contracts and segregation of stable and mature junction [80]. Therefore, these effects lead to actin polymerisation or actomyosin inactivation resulting in changing the formation of inter-epithelial adherens junctions. According to this evidence, the cytoskeleton regulates VEcadherin clustering, and VE-cadherin regulates cytoskeletal organisation and barrier stability alternately [80]. Thus, VE-cadherin can assist tumour cells to adhere to lymphatic vessels via loss of lymphatic permeability control and through its effect on cytoskeletal integrity.

The differences between E-cadherin, $\mathrm{N}$-cadherin and VE-cadherin can be ascribed to the different localisation of $\beta$-catenin. $\mathrm{N}$-cadherin and VE-cadherin are expressed in the nucleus and cytoplasm, respectively, while E-cadherin is expressed on the cell membrane. Therefore, Ecadherin levels are elevated in the presence of reduced $\mathrm{N}$-cadherin expression leading to the repression of EMT regulators and transforming the invasive mesenchymal phenotype to an epithelial phenotype prompting tumour cells to adhere to lymphatic vessels and establish LVI as revealed in a recent clinical study [79].

Vimentin is related to the adhesion and migration properties of tumour cells [81]. Gilles et al. [82] have observed that the accumulation of nuclear and cytoplasmic vimentin and $\beta$-catenin has a dual functional role in tumour cell migration and invasion by promoting a $\beta$-catenin/T-cell factor pathway in BC. Moreover, vimentin expression is transactivated as a result of the interaction between $\beta$-catenin and T-cell factor/lymphoid enhancer factor- 1 transcription factor family. In mammary carcinoma cell lines where $\beta$-catenin is found on the plasma membrane, vimentin is downregulated, while its level remains unchanged in the cytoplasmic and nuclear allocation of $\beta$-catenin [82]. Therefore, $\beta$-catenin acts as an EMT/MET regulator during cell migration. Liu et al. [83] have demonstrated that vimentin participates in the focal adhesion and cytoskeleton organisation and also regulates cancer cells' mechanical homeostasis. Hence, vimentin contributes to an aggressive tumour phenotype via LVI, because of its ability to enhance motility, change cancer cells' configuration and downregulate tumour cell adhesiveness [84].

\section{Tumour Cell Intravasation}

Intravasation is the process whereby malignant cells cross the endothelial barrier and invade lymphatic across the basement membrane [26]. The rate of tumour cell in- 
travasation is highly influenced by several factors involved in tumour cell invasion and migration and the interplay with the surrounding structures as described above [26]. Interaction between the tumour microenvironment and tumour cells at the intravasation site can activate the reciprocal secretion of EGF. EGF executes its actions through the EGF receptor to promote tumour cell migration and invasion into the lymphatic channels via transactivation of EGFR signalling by EP4 receptor pathway which is involved in the invadopodia formation [85]. Some authors have suggested that tumour cell intravasation plays a significant role in $\mathrm{BC}$ metastasis via attachment of endothelial cells to fibroblast-derived CXCL12 [86] where TGF- $\beta$ augments intravasation by amplifying penetration of microvessel walls [87]. Type IV collagenase, which can actively digest the ECM and basement membrane, enables malignant epithelial cells to migrate through the interstitial tissue and into lymphatic vessels facilitating the development of LVI [88]. Collections of BC cells can directly penetrate the lymphatic vessels through the action of cyclooxygenase (COX) 12 or COX15, which metabolises arachidonic acid to 12(S)-hydroxy-eicosatetraenoic acid (12[S]-HETE). Exposure to 12(S)-HETE transiently reduces their VE-cadherin expression resulting in migration of these cells [89]. In vivo $\mathrm{BC}$ murine models have shown that the transcription factor Twist enhances the process of intravasation, acting as an EMT-inducing transcription factor and promoting the rate of haematogenous intravasation and bone metastasis [90]. Despite the documented importance of tumour intravasation into lymphatic/vascular spaces, the driving mechanisms controlling the process are still incompletely characterised and therefore warrants further studies. VEcadherin regulates VEGFs and affects cancer cell migration through regulating actin-driven junction-associated intermittent lamellipodia [91]. Certain actions of VEGFs activate the C-C motif chemokine ligand 21 (CCL21), which interacts with $\mathrm{C}-\mathrm{C}$ motif chemokine receptor 7 (CCR7) that is located on the VE surface. The secretion of CCL21 is strongly affected by the upstream signalling of its receptor VEGFR3 and VEGF-C secretion by malignant cells [42]. Kim et al. [92] suggested that the Let-7a targeting of CCL21/CCR7 singling is a promising approach to prevent $\mathrm{BC}$ migration and invasion.

VEGFs are also involved in tumour cell migration as regulators of $\mathrm{BC}$ proliferation and tumour cell escape from apoptotic signals. This characteristic makes VEGFs a potential target candidate in BC patients in the neoadjuvant setting [93]. Arai et al. [94] suggested that VEGFs also play an essential role in trastuzumab therapy by min- imising the allocation of tumour cells to the lymphatic vessels in HER2-positive BC.

Podoplanin, which is expressed by lymphatic endothelial cells, induces the formation of a glycoprotein and is used as a specific lymphatic endothelial marker [95]. Podoplanin promotes migration, proliferation rate and invasiveness of malignant cells via increasing the RhoA activity [96]. Neri et al. [97] have shown that tumours with high expression of podoplanin have higher local migration and invasion than those with low podoplanin, suggesting podoplanin as a potential therapeutic target through preventing migration, using a podoplanin monoclonal antibody (NZ-1) and lectin (MASL) inhibition [98]. Knockdown studies with podoplanin siRNA have resulted in decreased cell proliferation and cell motility. Previous research study has shown that podoplanin could be a potential therapeutic target to prevent cancer cell migration via synthesis of phosphatase modular that may prevent cancer cell migration [99].

\section{The Role of Cancer Stem Cells in LVI}

Cancer stem cells (CSCs) play an important role in the $\mathrm{BC}$ progression by regulating tumourigenesis and resistance to therapeutic regimens. CSCs have high plasticity with reciprocal directions between stem and non-stem (differentiation) states $[100,101]$ with activation of the classical mesenchymal phenotype [102] and enhancement of the protrusive activation, which is a known migration hallmark, compared to differentiated cells [101]. Therefore, CSCs seem to control the alterations of the focal adhesion signalling dynamics that allow them to perform a rapid switching between migration/phenotype modes and that contributes to tumour cell movement through fibrous matrices and, hence, initiate a symbiotic environment that increases metastatic potency [101]. Indeed, EMT is a critical process underlying the ability of cancerous cells to migrate, cause LVI and metastasise [103]. CSCs in in situ breast carcinomas can transform into migrating cancer stem cells, which have the ability to disseminate and form metastatic colonies, by EMT [104]. It has been demonstrated that some CSC biomarkers such as ALDH1, CD44 and CD133 promote lymphatic metastasis of cancer cells $[105,106]$. A recent in vivo study demonstrated that CSCs play a key role in the BC tumour progression by creating a permissive environment for the collective cancer migration and invasion processes via controlling E-cadherin and $\mathrm{N}$-cadherin expression and guide the invasion and metastasis [107]. It has also been 
demonstrated that in hypoxic conditions, CSCs can indirectly enhance angiogenesis and lymphangiogenesis by expression of angiogenetic and lymphangiogenic factors such as VEGFR2. VEGFR2 also alters the morphology of CSCs to elongated endothelial-like cells [101]. Another in vitro BC study [108] has indicated that CSCs expressed endothelial markers CD31, VEGFR2 and FVIII when cultured in the presence of VEGF. This data provides further support for the role of CSCs in the development of LVI.

\section{Key LVI-Related Biomarkers}

There have been several studies attempting to identify target genes that play an essential role in LVI. Our group has recently published a bioinformatics study using RNA expression data to identify differentially expressed genes in LVI-positive and LVI-negative cases. Following a stringent approach, 99 genes were demonstrated as significantly associated with BC LVI whether being upregulated or downregulated [109].

In their study, Klahan et al. [21] identified 86 differentially expressed genes with LVI in BC, including 37 downregulated and 49 upregulated genes. Among these genes was EPAS1, which stimulates the production of VEGF, and TNFSF11, which is a receptor activator of nuclear factor kappa-B ligand; both enhanced mammary cell invasion, migration, and metastasis. Other genes included TNFSF11 and IL6ST that play important roles in cytokine-receptor interaction, which is the most enriched pathway related to LVI.

Focal adhesion kinase (FAK) is a cytoplasmic tyrosine kinase that is associated with a plethora of singling pathways fundamental to cell cancer migration, proliferation, death and tumour survival [110]. According to Golubovskaya et al. [111], high FAK levels correlated strongly with aggressive BC subtypes such as TN BC as well as with LVI, hence FAK might be a target for therapeutic intervention in these patients. Using pre-clinical mouse models of BC, a significant reduction in tumour growth was achieved by an anti-proliferative activity using a chemical inhibitor of FAK (BI 853520). Moreover, in vitro and in vivo suppression of FAK signalling in combination with chemotherapies improved chemo-cytotoxicity [112]. McCall et al. [113] showed that astaxanthin (ASX), a potent antioxidant, could play a critical role in preventing LVI by inhibiting tumour cell proliferation and migration through promoting apoptosis in BC cells compared with normal breast epithelial cells. ASX inhibits migration in the aggressive TN BC cell line by decreasing the inflammatory mediators within the tumour microenvironment such as TNF- $\alpha$, IL- 6 and IFN- $\gamma$ through NF $\kappa \beta$ inhibition, therefore rendering ASX a potential target to prevent LVI in BC [113]. Blocking migration would have a significant positive impact on patient outcome. Inhibiting the early events of cell migration from primary tumours into the circulatory or lymphatic systems will help reduce distant metastasis. Forkhead transcription factor family (FOXO) are tumour suppressor regulating cell proliferation and promoting apoptosis in BC. Recent in vitro studies have demonstrated that expression of FOXO6 promotes BC migration and invasion by aiding EMT [114]. Elevated FOXO6 in BCs could be, at least in part, due to reduced activity of the PI3K/AKT pathway. Normal adult tissues exhibit decreased FOXO6 expression levels in contrast to $\mathrm{BC}$, which showed increased expression; thus, it may be a potential candidate for BC therapy [115]. Others have indicated that FOXO3a is strongly associated with adverse clinicopathological parameters including EMT and poor patient outcome in TN BC and plays an essential role in enhancing tumour cell migration via TGF- $\beta 1$ triggered HGF-induced and MET-dependent migration in vitro [116]. The subcellular localisation of FOXO3a is important where phosphorylation of FOXO3a leads to its translocation from the nucleus to the cytoplasm [117]. For instance, in T-cell acute lymphoblastic leukaemia, FOXO3 is an indirect target of BMS-345541, selective IKK inhibitor. FOXO3a was reported to act as an EGFR inhibitor and increase chemosensitivity of cancer cells to lapatinib [118]. Consequently, FOXO6 and FOXO3a could be potential therapeutic targets to prevent LVI in BC.

The current proteomic, transcriptomic and genetic evolution is not enough to draw a precise molecular roadmap for LVI. Although this difficulty may reflect the complexity of the whole process, this review has highlighted some important biological players at the molecular level to further assist deciphering the mechanistic overlap between the cancer cell migration and the surrounding microenvironment in BC LVI.

\section{Future Directions and Conclusion}

Investigating a large cohort of early stage metastasisfree (both node metastasis and distant metastasis) BC that contains subgroups of LVI negative and LVI extensive tumours using multiplatform high throughput molecular techniques looking at differentiational expressed genes and pathways could help eliminate the impact of metastasis on the candidate gene lists. Although LVI is consid- 
ered as a prerequisite for tumour metastasis, there are multiple LVI-associated genes/proteins that do not generate metastasis. Banin-Hirata et al. [119] investigated a significant role of HER2-positive BC in LVI by enhancing the tumour microenvironment to support the tumour cell growth, stimulating invasion LVI and metastasis. There are several pathways related to cancer cell migration which are essential to the prevention of metastasis, such as P120 catenin, FAK, RhoA, paxillin and P130CAS pathways. Furthermore, other pathways which affect cancer cell angiogenesis (STAT3 pathway), survival (PI3K pathway) and proliferation (RAS pathway) might be candidates for preventing $\mathrm{BC} \mathrm{LVI/metastasis.} \mathrm{An} \mathrm{in-depth}$ understanding of these pathways will facilitate the exploration of those genes responsible for LVI in BC, thus could be helpful in pinpointing the target genes for therapeutic strategy and thus preventing $\mathrm{BC}$ metastasis.

In conclusion, invasion and migration are important phenomena required for the process of LVI. They are highly complex and overlapping; therefore, further mechanistic evaluation is necessary to explore the inter-relationship of these 2 processes in BC. This review has summarised the key factors associated with the BC cell invasion and migration and the interaction with the microenvironment. We propose that further exploration of the candidate genes/proteins will be a tool to interro- gate the metastatic cascade in $\mathrm{BC}$ and encourage a better understanding of LVI molecular mechanisms. Focusing on the migratory capacity and cancer cell spreading could be useful for tailoring the treatment regimens for aggressive BC subtypes.

\section{Acknowledgments}

Y.A.K. is supported and funded by Shaqra University, Kingdom of Saudi Arabia. We thank Innovate UK for funding (ISCF bid Ref. 18181).

\section{Disclosure Statement}

All authors declare that they have no conflict of interest.

\section{Funding Sources}

This research was supported and funded by the Saudi Arabia Ministry of Education Shaqra University. The authors are part of the PathLAKE digital pathology consortium. These new Centres are supported by a GBP 50 million investment from the Data to Early Diagnosis and Precision Medicine strand of the government's Industrial Strategy Challenge Fund, managed and delivered by UK Research and Innovation (UKRI).

\section{References}

1 Bray F, Ferlay J, Soerjomataram I, Siegel RL, Torre LA, Jemal A. Global cancer statistics 2018: GLOBOCAN estimates of incidence and mortality worldwide for 36 cancers in 185 countries. CA Cancer J Clin. 2018 Nov;68(6): 394-424.

2 DeSantis CE, Ma J, Goding Sauer A, Newman LA, Jemal A. Breast cancer statistics, 2017, racial disparity in mortality by state. CA Cancer J Clin. 2017 Nov;67(6):439-48.

3 Kozłowski J, Kozłowska A, Kocki J. Breast cancer metastasis - insight into selected molecular mechanisms of the phenomenon. Postepy Hig Med Dosw. 2015 Apr;69:44751.

4 Song YJ, Shin SH, Cho JS, Park MH, Yoon $\mathrm{JH}$, Jegal YJ. The role of lymphovascular invasion as a prognostic factor in patients with lymph node-positive operable invasive breast cancer. J Breast Cancer. 2011 Sep; 14(3): 198-203.

5 Aleskandarany MA, Sonbul SN, Mukherjee A, Rakha EA. Molecular Mechanisms Underlying Lymphovascular Invasion in Invasive Breast Cancer. Pathobiology. 2015 Sep;82(34):113-23

6 Rakha EA, Martin S, Lee AH, Morgan D, Pharoah PD, Hodi Z, et al. The prognostic sig- nificance of lymphovascular invasion in invasive breast carcinoma. Cancer. 2012 Aug; 118(15):3670-80.

7 Gooch JC, Schnabel F, Chun J, Pirraglia E, Troxel AB, Guth A, et al. A nomogram to predict factors associated with lymph node metastasis in ductal carcinoma in situ with microinvasion. Ann Surg Oncol. 2019 Dec; 26(13):4302-9.

8 Joosse SA, Gorges TM, Pantel K. Biology, detection, and clinical implications of circulating tumor cells. EMBO Mol Med. 2015 Jan; 7(1):1-11.

9 Ribelles N, Santonja A, Pajares B, Llácer C, Alba E. The seed and soil hypothesis revisited: current state of knowledge of inherited genes on prognosis in breast cancer. Cancer Treat Rev. 2014 Mar;40(2):293-9.

10 Weiss L, Ward PM. Cell detachment and metastasis. Cancer Metastasis Rev. 1983;2(2): 111-27.

11 Melzer C, von der Ohe J, Hass R. Breast carcinoma: from initial tumor cell detachment to settlement at secondary sites. BioMed Res Int. 2017;2017:8534371.

12 Pepper MS, Tille JC, Nisato R, Skobe M. Lymphangiogenesis and tumor metastasis. Cell Tissue Res. 2003 Oct;314(1):167-77.
13 Reyes N, Benedetti I, Bettin A, Rebollo J, Geliebter J. The small leucine rich proteoglycan fibromodulin is overexpressed in human prostate epithelial cancer cell lines in culture and human prostate cancer tissue. Cancer Biomark. 2016;16(1):191-202.

14 Mohammed RA, Martin SG, Mahmmod AM, Macmillan RD, Green AR, Paish EC, et al. Objective assessment of lymphatic and blood vascular invasion in lymph node-negative breast carcinoma: findings from a large case series with long-term follow-up. J Pathol. 2011 Feb;223(3):358-65.

15 Smith I, Procter M, Gelber RD, Guillaume S, Feyereislova A, Dowsett $M$, et al.; HERA study team. 2-year follow-up of trastuzumab after adjuvant chemotherapy in HER2-positive breast cancer: a randomised controlled trial. Lancet. 2007 Jan;369(9555):29-36.

16 Geyer CE, Forster J, Lindquist D, Chan S, Romieu CG, Pienkowski T, et al. Lapatinib plus capecitabine for HER2-positive advanced breast cancer. N Engl J Med. 2006 Dec; 355(26):2733-43.

17 Gajria D, Chandarlapaty S. HER2-amplified breast cancer: mechanisms of trastuzumab resistance and novel targeted therapies. Expert Rev Anticancer Ther. 2011 Feb;11(2):263-75. 
18 Huang F, Shi Q, Li Y, Xu L, Xu C, Chen F, et al. HER2/EGFR-AKT signaling switches TGF $\beta$ from inhibiting cell proliferation to promoting cell migration in breast cancer. Cancer Res. 2018 Nov;78(21):6073-85.

19 Baselga J, Cortés J, Kim SB, Im SA, Hegg R, Im YH, et al.; CLEOPATRA Study Group. Pertuzumab plus trastuzumab plus docetaxel for metastatic breast cancer. N Engl J Med. 2012 Jan;366(2):109-19.

20 Mannelqvist M, Wik E, Stefansson IM, Akslen LA. An 18-gene signature for vascular invasion is associated with aggressive features and reduced survival in breast cancer. PLoS One. 2014 Jun;9(6):e98787.

21 Klahan S, Wong HS, Tu SH, Chou WH, Zhang YF, Ho TF, et al. Identification of genes and pathways related to lymphovascular invasion in breast cancer patients: a bioinformatics analysis of gene expression profiles. TumourBiol.2017Jun;39(6):1010428317705573.

22 Fife CM, McCarroll JA, Kavallaris M. Movers and shakers: cell cytoskeleton in cancer metastasis. Br J Pharmacol. 2014 Dec;171(24): 5507-23.

23 Guan X. Cancer metastases: challenges and opportunities. Acta Pharm Sin B. 2015 Sep; 5(5):402-18.

24 Spano D, Heck C, De Antonellis P, Christofori G, Zollo M. Molecular networks that regulate cancer metastasis. Semin Cancer Biol. 2012 Jun;22(3):234-49.

25 Sabeh F, Shimizu-Hirota R, Weiss SJ. Protease-dependent versus -independent cancer cell invasion programs: three-dimensional amoeboid movement revisited. J Cell Biol. 2009 Apr;185(1):11-9.

26 Tsuji T, Ibaragi S, Hu GF. Epithelial-mesenchymal transition and cell cooperativity in metastasis. Cancer Res. 2009 Sep;69(18): 7135-9.

27 Alizadeh AM, Shiri S, Farsinejad S. Metastasis review: from bench to bedside. Tumour Biol. 2014 Sep;35(9):8483-523.

28 Chen LC, Tu SH, Huang CS, Chen CS, Ho CT, Lin HW, et al. Human breast cancer cell metastasis is attenuated by lysyl oxidase inhibitors through down-regulation of focal adhesion kinase and the paxillin-signaling pathway. Breast Cancer Res Treat. 2012 Aug; 134(3):989-1004.

29 Pula B, Wojnar A, Werynska B, Ambicka A, Kruczak A, Witkiewicz W, et al. Impact of different tumour stroma assessment methods regarding podoplanin expression on clinical outcome in patients with invasive ductal breast carcinoma. Anticancer Res. 2013 Apr; 33(4): 1447-55.

30 Suresh S. Biomechanics and biophysics of cancer cells. Acta Biomater. 2007 Jul;3(4): 413-38.

31 López-Colomé AM, Lee-Rivera I, BenavidesHidalgo R, López E. Paxillin: a crossroad in pathological cell migration. J Hematol Oncol. 2017 Feb;10(1):50.

32 Revach OY, Weiner A, Rechav K, Sabanay I, Livne A, Geiger B. Mechanical interplay be- tween invadopodia and the nucleus in cultured cancer cells. Sci Rep. 2015 Mar;5(1): 9466.

33 Weidmann MD, Surve CR, Eddy RJ, Chen X, Gertler FB, Sharma VP, et al. MenaINV dysregulates cortactin phosphorylation to promote invadopodium maturation. Sci Rep. 2016 Nov;6(1):36142.

34 Dadiani M, Kalchenko V, Yosepovich A, Margalit R, Hassid Y, Degani H, et al. Realtime imaging of lymphogenic metastasis in orthotopic human breast cancer. Cancer Res. 2006 Aug;66(16):8037-41.

35 Wong SY, Hynes RO. Lymphatic or hematogenous dissemination: how does a metastatic tumor cell decide? Cell Cycle. 2006 Apr;5(8): 812-7.

36 Perentes JY, Kirkpatrick ND, Nagano S, Smith EY, Shaver CM, Sgroi D, et al. Cancer cell-associated MT1-MMP promotes blood vessel invasion and distant metastasis in triple-negative mammary tumors. Cancer Res. 2011 Jul;71(13):4527-38

37 Veeravalli KK, Chetty C, Ponnala S, Gondi CS, Lakka SS, Fassett D, et al. MMP-9, uPAR and cathepsin B silencing downregulate integrins in human glioma xenograft cells in vitro and in vivo in nude mice. PLoS One. $2010 \mathrm{Jul}$; 5(7):e11583.

38 Rodriguez OC, Schaefer AW, Mandato CA, Forscher P, Bement WM, Waterman-Storer $\mathrm{CM}$. Conserved microtubule-actin interactions in cell movement and morphogenesis. Nat Cell Biol. 2003 Jul;5(7):599-609.

39 Leung E, Xue A, Wang Y, Rougerie P, Sharma VP, Eddy R, et al. Blood vessel endotheliumdirected tumor cell streaming in breast tumors requires the HGF/C-Met signaling pathway. Oncogene. 2017 May;36(19):268092.

40 Potter SM, Dwyer RM, Hartmann MC, Khan $S$, Boyle MP, Curran CE, et al. Influence of stromal-epithelial interactions on breast cancer in vitro and in vivo. Breast Cancer Res Treat. 2012 Jan;131(2):401-11.

41 Soysal SD, Tzankov A, Muenst SE. Role of the Tumor Microenvironment in Breast Cancer. Pathobiology. 2015 Sep;82(3-4):142-52.

42 Tutunea-Fatan E, Majumder M, Xin X, Lala PK. The role of CCL21/CCR7 chemokine axis in breast cancer-induced lymphangiogenesis. Mol Cancer. 2015 Feb;14(1):35.

43 Cichon MA, Degnim AC, Visscher DW, Radisky DC. Microenvironmental influences that drive progression from benign breast disease to invasive breast cancer. J Mammary Gland Biol Neoplasia. 2010 Dec;15(4):389-97.

44 Wessels DJ, Pradhan N, Park YN, Klepitsch MA, Lusche DF, Daniels KJ, et al. Reciprocal signaling and direct physical interactions between fibroblasts and breast cancer cells in a 3D environment. PLoS One. 2019 Jun; 14(6):e0218854.

45 Kim Y, Stolarska MA, Othmer HG. The role of the microenvironment in tumor growth and invasion. Prog Biophys Mol Biol. 2011 Aug;106(2):353-79.
46 Pula B, Wojnar A, Witkiewicz W, Dziegiel P, Podhorska-Okolow M. Podoplanin expression in cancer-associated fibroblasts correlates with VEGF-C expression in cancer cells of invasive ductal breast carcinoma. Neoplasma. 2013;60(5):516-24.

47 Wang M, Zhang J, Huang Y, Ji S, Shao G, Feng $\mathrm{S}$, et al. Cancer-associated fibroblasts autophagy enhances progression of triple-negative breast cancer cells. Med Sci Monit. 2017 Aug; 23:3904-12.

48 Suo J, Medina D, Herrera S, Zheng ZY, Jin L, Chamness GC, et al. Int6 reduction activates stromal fibroblasts to enhance transforming activity in breast epithelial cells. Cell Biosci. 2015 Mar;5(1): 10.

49 González LO, González-Reyes S, Marín L, González L, González JM, Lamelas ML, et al. Comparative analysis and clinical value of the expression of metalloproteases and their inhibitors by intratumour stromal mononuclear inflammatory cells and those at the invasive front of breast carcinomas. Histopathology. 2010 Dec;57(6):862-76.

50 Coussens LM, Werb Z. Inflammation and cancer. Nature. 2002 Dec;420(6917):860-7.

51 Mantovani A, Marchesi F, Porta C, Sica A, Allavena $\mathrm{P}$. Inflammation and cancer: breast cancer as a prototype. Breast. 2007 Dec; 16(Suppl 2):S27-33.

$52 \mathrm{Xu}$ T, He BS, Liu XX, Hu XX, Lin K, Pan YQ, et al. The predictive and prognostic role of stromal tumor-infiltrating lymphocytes in HER2positive breast cancer with trastuzumab-based treatment: a meta-analysis and systematic review. J Cancer. 2017 Oct;8(18):3838-48.

53 Bajwa R, Cheema A, Khan T, Amirpour A, Paul A, Chaughtai S, et al. Adverse effects of immune checkpoint inhibitors (programmed death-1 inhibitors and cytotoxic T-lymphocyte-associated protein- 4 inhibitors): results of a retrospective study. J Clin Med Res. 2019 Apr;11(4):225-36.

54 Loi S, Sirtaine N, Piette F, Salgado R, Viale G, Van Eenoo F, et al. Prognostic and predictive value of tumor-infiltrating lymphocytes in a phase III randomized adjuvant breast cancer trial in node-positive breast cancer comparing the addition of docetaxel to doxorubicin with doxorubicin-based chemotherapy: BIG 02-98. J Clin Oncol. 2013 Mar;31(7):860-7.

55 Rakha EA, Aleskandarany M, El-Sayed ME, Blamey RW, Elston CW, Ellis IO, et al. The prognostic significance of inflammation and medullary histological type in invasive carcinoma of the breast. Eur J Cancer. 2009 Jul; 45(10):1780-7

56 Althobiti M, Aleskandarany MA, Joseph C, Toss M, Mongan N, Diez-Rodriguez M, et al. Heterogeneity of tumour-infiltrating lymphocytes in breast cancer and its prognostic significance. Histopathology. 2018 Dec;73(6):887-96.

57 Liu S, Lachapelle J, Leung S, Gao D, Foulkes WD, Nielsen TO. CD8+ lymphocyte infiltration is an independent favorable prognostic indicator in basal-like breast cancer. Breast Cancer Res. 2012 Mar;14(2):R48. 
58 Kassan M, Galan M, Partyka M, Trebak M, Matrougui K. Interleukin-10 released by CD4(+)CD25(+) natural regulatory T cells improves microvascular endothelial function through inhibition of NADPH oxidase activity in hypertensive mice. Arterioscler Thromb Vasc Biol. 2011 Nov;31(11):253442.

59 Merlo A, Casalini P, Carcangiu ML, Malventano C, Triulzi T, Mènard S, et al. FOXP3 expression and overall survival in breast cancer. J Clin Oncol. 2009 Apr;27(11):1746-52.

60 Tumeh PC, Harview CL, Yearley JH, Shintaku IP, Taylor EJ, Robert L, et al. PD-1 blockade induces responses by inhibiting adaptive immune resistance. Nature. 2014 Nov; 515(7528):568-71.

61 Mendoza-Rodríguez MG, Ayala-Sumuano JT, García-Morales L, Zamudio-Meza H, Pérez-Yepez EA, Meza I. IL-1 $\beta$ inflammatory cytokine-induced TP63 isoform $\triangle$ NP63a signaling cascade contributes to cisplatin resistance in human breast cancer cells. Int J Mol Sci. 2019 Jan;20(2):E270.

62 Zhu X, Mulcahy LA, Mohammed RA, Lee AH, Franks HA, Kilpatrick L, et al. IL-17 expression by breast-cancer-associated macrophages: IL-17 promotes invasiveness of breast cancer cell lines. Breast Cancer Res. 2008; 10(6):R95.

63 Ahmad N, Ammar A, Storr SJ, Green AR, Rakha E, Ellis IO, et al. IL-6 and IL-10 are associated with good prognosis in early stage invasive breast cancer patients. Cancer Immunol Immunother. 2018 Apr;67(4):537-49.

64 Fantin A, Vieira JM, Gestri G, Denti L, Schwarz Q, Prykhozhij S, et al. Tissue macrophages act as cellular chaperones for vascular anastomosis downstream of VEGF-mediated endothelial tip cell induction. Blood. 2010 Aug;116(5):829-40.

65 Outtz HH, Tattersall IW, Kofler NM, Steinbach N, Kitajewski J. Notch1 controls macrophage recruitment and Notch signaling is activated at sites of endothelial cell anastomosis during retinal angiogenesis in mice. Blood. 2011 Sep;118(12):3436-9.

66 Smyth MJ, Dunn GP, Schreiber RD. Cancer immunosurveillance and immunoediting: the roles of immunity in suppressing tumor development and shaping tumor immunogenicity. Adv Immunol. 2006;90:1-50.

67 Seo N, Shirakura Y, Tahara Y, Momose F, Harada $\mathrm{N}$, Ikeda $\mathrm{H}$, et al. Activated $\mathrm{CD} 8+\mathrm{T}$ cell extracellular vesicles prevent tumour progression by targeting of lesional mesenchymal cells. Nat Commun. 2018 Jan;9(1):435.

68 Ward R, Sims AH, Lee A, Lo C, Wynne L, Yusuf $\mathrm{H}$, et al. Monocytes and macrophages, implications for breast cancer migration and stem cell-like activity and treatment. Oncotarget. 2015 Jun;6(16):14687-99.

69 Solinas G, Germano G, Mantovani A, Allavena $P$. Tumor-associated macrophages (TAM) as major players of the cancer-related inflammation. J Leukoc Biol. 2009 Nov;86(5): 1065-73.
70 Gratchev A. TGF- $\beta$ signalling in tumour associated macrophages. Immunobiology. 2017 Jan;222(1):75-81.

71 Balkwill F. TNF-alpha in promotion and progression of cancer. Cancer Metastasis Rev. 2006 Sep;25(3):409-16.

72 Pittet MJ. Behavior of immune players in the tumor microenvironment. Curr Opin Oncol. 2009 Jan;21(1):53-9.

73 Ding M, Fu X, Tan H, Wang R, Chen Z, Ding $S$. The effect of vascular endothelial growth factor $\mathrm{C}$ expression in tumor-associated macrophages on lymphangiogenesis and lymphatic metastasis in breast cancer. Mol Med Rep. 2012 Nov;6(5):1023-9.

74 Richard V, Kindt N, Saussez S. Macrophage migration inhibitory factor involvement in breast cancer (Review). Int J Oncol. 2015 Nov; 47(5):1627-33.

75 Zhang J, Zhang G, Yang S, Qiao J, Li T, Yang $S$, et al. Macrophage migration inhibitory factor regulating the expression of VEGF-C through MAPK signal pathways in breast cancer MCF-7 cell. World J Surg Oncol. 2016 Feb;14(1):51.

76 Wolczyk D, Zaremba-Czogalla M, Hryniewicz-Jankowska A, Tabola R, Grabowski K, Sikorski AF, et al. TNF- $\alpha$ promotes breast cancer cell migration and enhances the concentration of membrane-associated proteases in lipid rafts. Cell Oncol (Dordr). 2016 Aug; 39(4):353-63.

77 Schoppmann SF, Tamandl D, Roberts L, Jomrich G, Schoppmann A, Zwrtek R, et al. HER2/neu expression correlates with vascular endothelial growth factor-C and lymphangiogenesis in lymph node-positive breast cancer. Ann Oncol. 2010 May;21(5):955-60.

78 Conway EM, Collen D, Carmeliet P. Molecular mechanisms of blood vessel growth. Cardiovasc Res. 2001 Feb;49(3):507-21.

79 Rezaei M, Friedrich K, Wielockx B, Kuzmanov A, Kettelhake A, Labelle M, et al. Interplay between neural-cadherin and vascular endothelial-cadherin in breast cancer progression. Breast Cancer Res. 2012 Dec;14(6):R154

80 Giannotta M, Trani M, Dejana E. VE-cadherin and endothelial adherens junctions: active guardians of vascular integrity. Dev Cell. 2013 Sep;26(5):441-54.

81 Vuoriluoto K, Haugen H, Kiviluoto S, Mpindi JP, Nevo J, Gjerdrum C, et al. Vimentin regulates EMT induction by Slug and oncogenic $\mathrm{H}$-Ras and migration by governing Axl expression in breast cancer. Oncogene. 2011 Mar;30(12):1436-48.

82 Gilles C, Polette M, Mestdagt M, NawrockiRaby B, Ruggeri P, Birembaut P, et al. Transactivation of vimentin by beta-catenin in human breast cancer cells. Cancer Res. 2003 May;63(10):2658-64.

83 Liu CY, Lin HH, Tang MJ, Wang YK. Vimentin contributes to epithelial-mesenchymal transition cancer cell mechanics by mediating cytoskeletal organization and focal adhesion maturation. Oncotarget. 2015 Jun;6(18): 15966-83.
84 Roussos ET, Keckesova Z, Haley JD, Epstein DM, Weinberg RA, Condeelis JS. AACR special conference on epithelial-mesenchymal transition and cancer progression and treatment. Cancer Res. 2010 Oct;70(19):7360-4.

85 Tönisen F, Perrin L, Bayarmagnai B, van den Dries K, Cambi A, Gligorijevic B. EP4 receptor promotes invadopodia and invasion in human breast cancer. Eur J Cell Biol. 2017 Mar;96(2):218-26.

86 Ahirwar DK, Nasser MW, Ouseph MM, Elbaz M, Cuitiño MC, Kladney RD, et al. Fibroblastderived CXCL12 promotes breast cancer metastasis by facilitating tumor cell intravasation. Oncogene. 2018 Aug;37(32):4428-42.

87 Giampieri S, Manning C, Hooper S, Jones L, Hill CS, Sahai E. Localized and reversible TGFbeta signalling switches breast cancer cells from cohesive to single cell motility. Nat Cell Biol. 2009 Nov;11(11):1287-96.

88 Morikawa K, Walker SM, Nakajima M, Pathak S, Jessup JM, Fidler IJ. Influence of organ environment on the growth, selection, and metastasis of human colon carcinoma cells in nude mice. Cancer Res. 1988 Dec; 48(23):6863-71.

89 Madlener S, Saiko P, Vonach C, Viola K, Hut$\operatorname{tary} \mathrm{N}$, Stark N, et al. Multifactorial anticancer effects of digalloyl-resveratrol encompass apoptosis, cell-cycle arrest, and inhibition of lymphendothelial gap formation in vitro. $\mathrm{Br} \mathrm{J}$ Cancer. 2010 Apr;102(9):1361-70.

90 Croset M, Goehrig D, Frackowiak A, Bonnelye E, Ansieau S, Puisieux A, et al. TWIST1 expression in breast cancer cells facilitates bone metastasis formation. J Bone Miner Res. 2014 Aug;29(8):1886-99.

91 Cao J, Ehling M, März S, Seebach J, Tarbashevich K, Sixta T, et al. Polarized actin and VE-cadherin dynamics regulate junctional remodelling and cell migration during sprouting angiogenesis. Nat Commun. 2017 $\operatorname{Dec} ; 8(1): 2210$.

92 Kim SJ, Shin JY, Lee KD, Bae YK, Sung KW, Nam SJ, et al. MicroRNA let-7a suppresses breast cancer cell migration and invasion through downregulation of C-C chemokine receptor type 7. Breast Cancer Res. 2012 Jan; 14(1):R14.

93 Wang RX, Chen S, Huang L, Zhou Y, Shao ZM. Monitoring Serum VEGF in Neoadjuvant Chemotherapy for Patients with Triple-Negative Breast Cancer: A New Strategy for Early Prediction of Treatment Response and Patient Survival. Oncologist. 2019 Jun;24(6):753-61.

94 Arai RJ, Petry V, Hoff PM, Mano MS. Serum levels of VEGF and MCSF in HER2+ / HER2breast cancer patients with metronomic neoadjuvant chemotherapy. Biomark Res. 2018 Jun;6(1):20.

95 Rudno-Rudzinska J, Kielan W, Grzebieniak Z, Dziegiel P, Donizy P, Mazur G, et al. High density of peritumoral lymphatic vessels measured by D2-40/podoplanin and LYVE-1 expression in gastric cancer patients: an excellent prognostic indicator or a false friend? Gastric Cancer. 2013 Oct;16(4):513-20. 
96 Suchanski J, Tejchman A, Zacharski M, Piotrowska A, Grzegrzolka J, Chodaczek G, et al. Podoplanin increases the migration of human fibroblasts and affects the endothelial cell network formation: a possible role for cancer-associated fibroblasts in breast cancer progression. PLoS One. 2017 Sep; 12(9): 0184970.

97 Neri S, Ishii G, Hashimoto H, Kuwata T, Nagai K, Date H, et al. Podoplanin-expressing cancer-associated fibroblasts lead and enhance the local invasion of cancer cells in lung adenocarcinoma. Int J Cancer. 2015 Aug;137(4):784-96.

98 Ochoa-Alvarez JA, Krishnan H, Pastorino JG, Nevel E, Kephart D, Lee JJ, et al. Antibody and lectin target podoplanin to inhibit oral squamous carcinoma cell migration and viability by distinct mechanisms. Oncotarget. 2015 Apr;6(11):9045-60.

99 Krishnan H, Ochoa-Alvarez JA, Shen Y, Nevel E, Lakshminarayanan M, Williams $\mathrm{MC}$, et al. Serines in the intracellular tail of podoplanin (PDPN) regulate cell motility. J Biol Chem. 2013 Apr;288(17):12215-21.

100 Cabrera MC, Hollingsworth RE, Hurt EM. Cancer stem cell plasticity and tumor hierarchy. World J Stem Cells. 2015 Jan;7(1):2736.

101 Ray A, Slama ZM, Morford RK, Madden SA, Provenzano PP. Enhanced directional migration of cancer stem cells in $3 \mathrm{D}$ aligned collagen matrices. Biophys J. 2017 Mar; 112(5):1023-36.

102 Lämmermann T, Sixt M. Mechanical modes of 'amoeboid' cell migration. Curr Opin Cell Biol. 2009 Oct;21(5):636-44.

103 Hayashida T, Jinno H, Kitagawa Y, Kitajima $\mathrm{M}$. Cooperation of cancer stem cell properties and epithelial-mesenchymal transition in the establishment of breast cancer metastasis. J Oncol. 2011;2011:591427.
104 Brabletz T, Jung A, Spaderna S, Hlubek F, Kirchner T. Opinion: migrating cancer stem cells - an integrated concept of malignant tumour progression. Nat Rev Cancer. 2005 Sep;5(9):744-9.

105 Wakamatsu Y, Sakamoto N, Oo HZ, Naito Y, Uraoka N, Anami K, et al. Expression of cancer stem cell markers ALDH1, CD44 and CD133 in primary tumor and lymph node metastasis of gastric cancer. Pathol Int. 2012 Feb;62(2):112-9.

106 Holah NS, Aiad HA, Asaad NY, Elkhouly EA, Lasheen AG. Evaluation of the role of ALDH1 as cancer stem cell marker in colorectal carcinoma: an immunohistochemical study. J Clin Diagn Res. 2017 Jan; 11(1):EC17-23.

107 Quan Q, Wang X, Lu C, Ma W, Wang Y, Xia $\mathrm{G}$, et al. Cancer stem-like cells with hybrid epithelial/mesenchymal phenotype leading the collective invasion. Cancer Sci. 2020 Feb; 111(2):467-76.

108 Bussolati B, Grange C, Sapino A, Camussi G Endothelial cell differentiation of human breast tumour stem/progenitor cells. J Cell Mol Med. 2009 Feb;13(2):309-19.

109 Kurozumi S, Joseph C, Sonbul S, Alsaeed S, Kariri Y, Aljohani A, et al. A key genomic subtype associated with lymphovascular invasion in invasive breast cancer. Br J Cancer. 2019 Jun; 120(12):1129-36.

110 Tiede S, Meyer-Schaller N, Kalathur RK, Ivanek R, Fagiani E, Schmassmann P, et al. The FAK inhibitor BI 853520 exerts anti-tumor effects in breast cancer. Oncogenesis. 2018 Sep;7(9):73.

111 Golubovskaya VM, Ylagan L, Miller A, Hughes M, Wilson J, Wang D, et al. High focal adhesion kinase expression in breast carcinoma is associated with lymphovascular invasion and triple-negative phenotype. BMC Cancer. 2014 Oct;14(1):769.
112 Kang Y, Hu W, Ivan C, Dalton HJ, Miyake $\mathrm{T}$, Pecot CV, et al. Role of focal adhesion kinase in regulating YB-1-mediated paclitaxel resistance in ovarian cancer. J Natl Cancer Inst. 2013 Oct;105(19):1485-95.

113 McCall B, McPartland CK, Moore R, FrankKamenetskii A, Booth BW. Effects of astaxanthin on the proliferation and migration of breast cancer cells in vitro. Antioxidants (Basel). 2018 Oct;7(10):135.

114 Ye H, Duan M. Downregulation of FOXO6 in breast cancer promotes epithelial-mesenchymal transition and facilitates migration and proliferation of cancer cells. Cancer Manag Res. 2018 Oct;10:5145-56.

115 Lallemand F, Petitalot A, Vacher S, de Koning L, Taouis K, Lopez BS, et al. Involvement of the FOXO6 transcriptional factor in breast carcinogenesis. Oncotarget. 2017 Dec;9(7):7464-75.

116 Rehman A, Kim Y, Kim H, Sim J, Ahn H, Chung MS, et al. FOXO3a expression is associated with lymph node metastasis and poor disease-free survival in triple-negative breast cancer. J Clin Pathol. 2018 Sep;71(9): 806-13.

117 Nielsen MD, Luo X, Biteau B, Syverson K, Jasper H. 14-3-3 Epsilon antagonizes FoxO to control growth, apoptosis and longevity in Drosophila. Aging Cell. 2008 Oct;7(5): 688-99.

118 Liu Y, Ao X, Ding W, Ponnusamy M, Wu W, Hao X, et al. Critical role of FOXO3a in carcinogenesis. Mol Cancer. 2018 Jul;17(1):104.

119 Banin-Hirata BK, de Oliveira CE, LosiGuembarovski R, Ozawa PM, Vitiello GA, de Almeida FC, et al. The prognostic value of regulatory $\mathrm{T}$ cells infiltration in HER2enriched breast cancer microenvironment. Int Rev Immunol. 2018 May;37(3):144-50. 